\title{
ASPECTOS BIOLÓGICOS DE Sternechus subsignatus EM SOJA NO SISTEMA PLANTIO DIRETO
}

\author{
BIOLOGICAL ASPECTS OF Sternechus subsignatus \\ IN SOYBEAN UNDER NO-TILLAGE SYSTEM
}

\author{
Mauro Tadeu Braga da Silva ${ }^{1}$
}

\section{RESUMO}

Aspectos biológicos de Sternechus subsignatus Boheman (Coleoptera: Curculionidae) foram investigados em lavouras comerciais de soja (Glycine max L.) que adotam o plantio direto, no município de Cruz Alta (RS), durante o período de novembro de 1989 a dezembro de 1991. O inseto mostrou-se univoltino, com uma única geração por ano, desenvolvendo-se em épocas bem definidas: adultos nas plantas de dezembro a março, ovos e larvas nas plantas de dezembro a abril, larvas no solo de fevereiro a novembro e pupas e adultos no solo de setembro a dezembro. O estágio larval, no solo, foi o mais longo do ciclo biológico do inseto. A longevidade de adultos nas plantas foi de 112,5 e 62,9 dias para fêmeas e machos, respectivamente. $O$ número de ovos por fêmea foi de 158,4 e a sua viabilidade foi de $89,9 \%$.

Palavras-chave: Tamanduá-da-soja, ciclo evolutivo,sistema de cultivo.

\section{SUMMARY}

Biological aspects of Sternechus subsignatus Boheman (Coleoptera: Curculionidae) were investigated in commercial fields cultivated to soybean (Glycine max L.) under no-tillage system, in Rio Grande do Sul State, from November 1989 to December 1991. S. subsignatus showed one generation a year, with the stages occurring in well defined dates: adults were found form December to March, eggs and larvae in the plants from December to April, larvae in the soil from February to November and pupae and adults in the soil from September to December. The larval stage, in the soil, was the longest period of the life cycle. The duration stage of adults females and males in the plants was 112.5 and 62.9 days, respectivelly. The average number of eggs per female was 158.4 and egg viability was the $89.9 \%$.

Key words: Sternechus subsignatus, evolutive cycle, tillage system.

\section{INTRODUÇÃO}

Na tribo Sternechini foram listados várias espécies do gênero Sternechus (Coleoptera: Curculionidae), conforme MENDES (1957). Dois destes curculionídeos têm sido citados, no Brasil, como causadores de prejuízos de importância econômica em culturas de interesse agrícola. BONDAR (1930) relatou o ataque de $\boldsymbol{S}$. uncipennis Germar sobre vagens de feijão de porco. S. subsignatus Boheman foi observado danificando plantas de feijão (SILVA et $\boldsymbol{a l} ., 1968)$ e de soja (CORSEUIL et al., 1974; PANIZZI et al., 1977).

Com relação a $\boldsymbol{S}$. subsignatus, denominado vulgarmente de tamanduá-da-soja, ROSADO NETO (1987) menciona sua ampla distribuição no território brasileiro, ocorrendo nos domínios da Mata Atlântica das regiões Sul, Sudeste e Nordeste e no cerrado da região Centro-Oeste até o sul da Mata Amazônica. Na cultura da soja, têm sido registradas infestações significativas do inseto em lavouras localizadas dentro da área tradicional de cultivo desta oleaginosa, compreendendo os Estados do RS, SC e PR (HOFFMANN-CAMPO et al., 1990). Segundo esses autores, no Paraná, os maiores ataques têm sido verificados nas regiões mais frias e, nestas, onde é feita a semeadura direta da soja. SILVA \& KLEIN (1997) concluíram que o plantio direto favorece, e a mobilização do solo com arado e grade desfavorece o ataque deste inseto às plantas de soja. Embora HOFFMANN-CAMPO et al. (1991) e LORINI (1997) tenham estudado o ciclo biológico

\footnotetext{
${ }^{1}$ Engenheiro agrônomo, Mestre, FUNDACEP FECOTRIGO, CP. 10, 98100-970, Cruz Alta, RS. E-mail: fundacep@azcomnet.com.br.
} Recebido para publicação em 10.06.98. Aprovado em 02.09 .98 
de $\boldsymbol{S}$. subsignatus, tem havido maior interesse dos pesquisadores de outras regiões pela pesquisa deste inseto, principalmente devido aos recentes registros do aumento de áreas infestadas pela praga em diversas regiões produtoras de soja do RS.

Este experimento foi conduzido com o objetivo de se conhecer a biologia e a dinâmica populacional, além da descrição e do comportamento de $\boldsymbol{S}$. subsignatus, nas plantas de soja e no solo sob sistema plantio direto, visando à obtenção de subsídios para o seu manejo.

\section{MATERIAL E MÉTODOS}

Os experimentos foram conduzidos em Cruz Alta - RS (altitude $=473 \mathrm{~m}$, latitude $=$ $28^{0} 38^{\prime} 21^{\prime \prime}$ e longitude $53^{0} 36^{\prime} 42^{\prime \prime}$ '), num Latossolo Vermelho-escuro, textura argilosa, manejado no sistema plantio direto, com soja (no verão) e trigoaveia (no inverno), desde 1987. Utilizou-se o cultivar Cobb, semeado em 16/11/1989 e 13/11/1990, na mesma área, numa densidade de 25 sementes/m e espaçamento de $0,45 \mathrm{~m}$ entre fileira.

Para registrar a ocorrência dos estágios de S. subsignatus na planta, foram realizadas amostragens semanais de novembro a abril, em 1989/90 e 90/91. Foram examinadas, ao acaso, dez amostras compostas por 40 plantas de soja presentes em $2 \mathrm{~m}$ de fileira e os adultos, os ovos e as larvas coletados e contados. Com os dados obtidos para cada estágio, calcularam-se as médias mensais $(n=4)$ das densidades populacionais, para cada ano agrícola.

Para definir a ocorrência dos estágios de S. subsignatus no solo, foram realizadas amostragens semanais de janeiro a dezembro, em 1990 e 1991. Foram escavadas, ao acaso, cinco amostras de solo de $0,2 \times 1,0 \times 0,3 \mathrm{~m}$ de profundidade, equivalentes a uma área superficial de $1 \mathrm{~m}^{2}$, sendo as larvas hibernantes, pupas e adultos separados do solo através de uma peneira com malha de $5 \mathrm{~mm}$. Com os dados obtidos para cada estágio, calcularam-se as médias mensais $(\mathrm{n}=4)$ das densidades populacionais, para cada ano agrícola.

Para estudar o desempenho reprodutivo e a sobrevivência, 20 casais de $\boldsymbol{S}$. subsignatus foram acompanhados em laboratório (temperatura de $25 \pm 2^{\circ} \mathrm{C}$, UR de $70 \pm 10 \%$ e sem controle de luz). Estes casais foram coletados recém emergidos do solo em gaiolas de $1,0 \times 1,0 \times 0,6 \mathrm{~m}$ de altura, em novembro de 1990, e sexados segundo ROSADO NETO (1987). Cada casal foi colocado em um frasco de vidro $(6,0 \mathrm{~cm}$ de diâmetro x $12,5 \mathrm{~cm}$ de altura) e alimentado com haste de soja, a qual serviu como substrato para postura. Diariamente, o alimento foi substituído, os adultos vivos ou mortos contados e os ovos coletados, contados e individualizados em placa de petri com papel filtro umedecido em água destilada. Avaliou-se a fertilidade das fêmeas (número de ovos viáveis x 100), dividindo-se este valor pelo número total de ovos coletados. Para obter os dados biométricos, foram coletados duzentos adultos (metade em dezembro de 1990 e a outra metade em dezembro de 1991) e avaliadas as seguintes variáveis: peso, comprimento e largura. As médias dos dados de longevidade e de biometria foram comparadas pelo teste "t" de Student em nível de 5\% de significância.

\section{RESULTADOS E DISCUSSÃO}

Os adultos de $\boldsymbol{S}$. subsignatus apareceram nas plantas de soja desde dezembro (02) até março (20), com maior densidade populacional durante o mês de dezembro (figura 1A). Para se alimentar, rasparam e desfiaram os tecidos da haste principal e, eventualmente, os ramos laterais e pecíolos das folhas. Quando o ataque ocorreu no início de desenvolvimento das plantas, a gema apical foi atingida e o dano foi irreversível, resultando no desfiamento total da haste principal, que morreu lentamente, e na redução da população de plantas na área. $\mathrm{O}$ estudo de sobrevivência mostrou maior longevidade das fêmeas em relação aos machos, com 112,5 e 62,9 dias, respectivamente (tabela 1). Os adultos coletados em dezembro de 1991 apresentaram menor comprimento e peso daqueles coletados em dezembro de 1990 (tabela 2).

Foram encontrados ovos desde dezembro (14) até abril (03) na haste principal e, eventualmente, no ramo lateral e até no pecíolo, com pico populacional no início de janeiro (figura 1B). Os ovos foram postos em orifícios protegidos pelas fibras do tecido cortado da epiderme (casca), por ocasião do anelamento feito pela fêmea para realizar a postura, e apresentaram coloração amarelada e forma ovalada. A incubação dos ovos foi de 5 dias, com um intervalo de variação de 3 a 9 dias $(n=2800$ ovos). O número médio de ovos por fêmea foi de 158,4 e, destes, 141,8 apresentaram emergência de larvas, representando uma viabilidade de $89,9 \%$ (tabela 1).

Larvas de diferentes tamanhos foram encontradas no interior da haste principal, na região do anelamento realizado pela fêmea para a postura, de dezembro (20) até abril (23), com maior densidade populacional registrada no final de janeiro e início de fevereiro (figura 1C). Elas apresentaram-se ápodes, recurvadas e corpo cilíndrico do tipo curculioniforme, cabeça diferenciada e quitinizada de coloração castanho-escura e o corpo branco-amarelado. As 


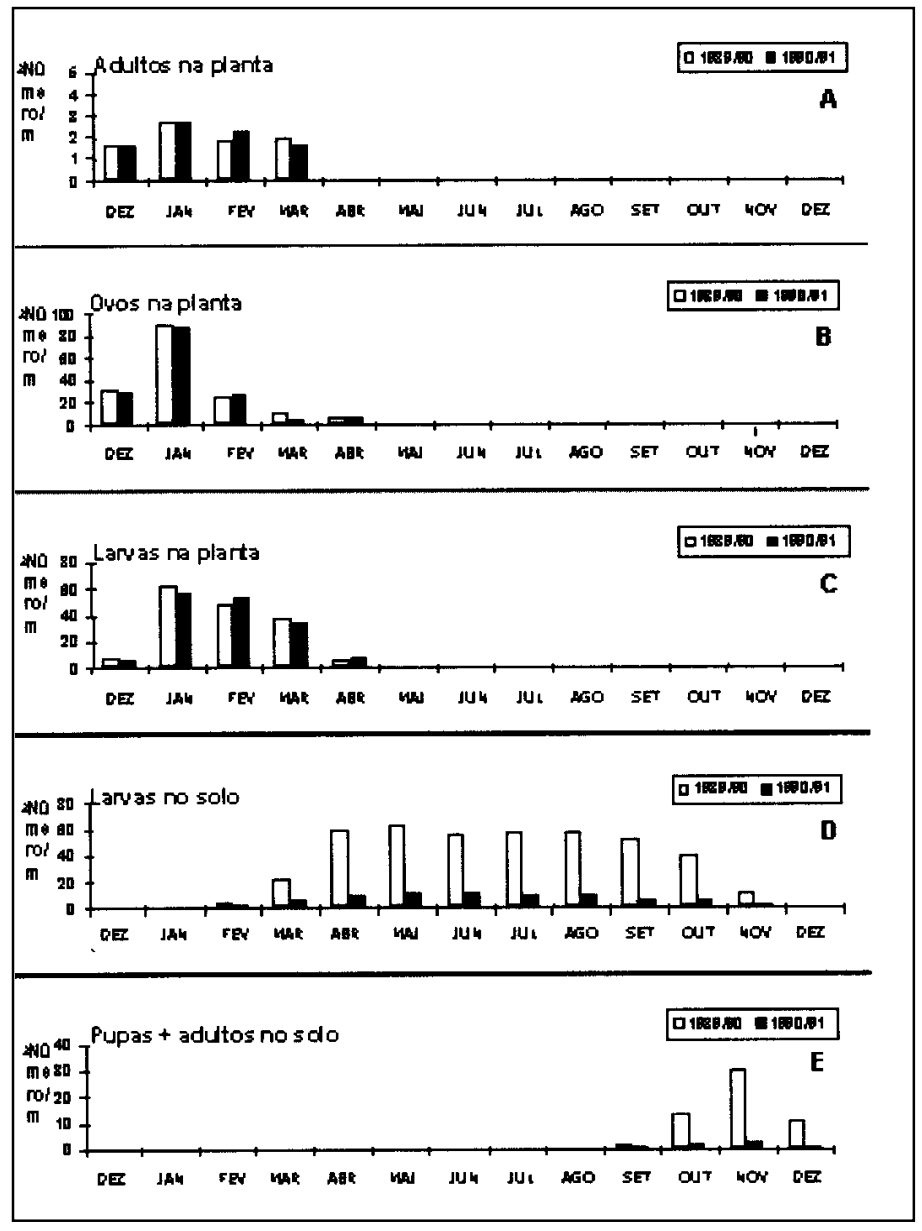

Figura 1 Ciclo evolutivo, adultos na planta (A), ovos na planta (B), larvas na planta (C), larvas no solo (D), pupas + adultos no solo (E) e densidade populacional de Sternechus subsignatus, em soja sobre condições naturais de plantio direto, para dois anos agrícolas 1989/90 e

multaneamente a esta fase apareceram os adultos (figura 1E), a partir da metade de outubro (15) até o final de dezembro (31), que permaneceram por alguns dias dentro da câmara, antes da emergência do solo, período este não determinado neste estudo. Apresentaram-se com coloração preta e listras amarelas na parte dorsal do tórax próxima da cabeça e nos élitros, formados por diminutas escamas. O rostro é largo e prolongado em um bico grosso e curto, aparecendo na extremidade as peças bucais. Em contato com o ambiente, a coloração branco-amarelada das listras presentes no corpo do adulto foi substituída pelo amarelointenso.

Embora o aparecimento dos adultos sobre as plantas tenha sido observado apenas no início de dezembro, pode ocorrer variação entre áreas, regiões e anos e, inclusive, dentro da mesma área, região e ano, devido ao ciclo de vida do inseto ter sincronia com a época de semeadura da soja, além do prolongado período de emergência dos adultos do solo. Segundo SILVA (1998), este período apresenta duração aproximada de dois meses, a partir do início de novembro até o final de dezembro, sendo a saída das câmaras escalonada dentro deste período.

Embora a sobrevivência de fêmeas e machos não acasalados não tenha sido objeto de avaliação, a constatação da maior sobrevivência de fêmeas, em comparação a machos (tabela 1), deve estar relacionada à maior reserva de energia que possuem, a qual perdem quando acasaladas e produzem ovos,

larvas alimentaram-se da medula da haste principal, destruindo o sistema vascular ao mastigar com suas mandíbulas, provocando reação dos tecidos vegetais e formação de uma calota ou galha. Essa deformação é a tentativa da planta de recompor a translocação normal, tornando a planta frágil acima dela, que quebra com facilidade pela ação mecânica (tráfego de máquinas, animais, etc.) ou do vento. No inicio de fevereiro (07), a larva foi ao solo, entrando em hibernação, não se alimentando e permanecendo na câmara até o início de novembro (11), quando inicia a próxima safra de soja (figura 1D).

As pupas apresentaram-se de coloração branco-amarelada e do tipo livre ou exarada, cujos apêndices toráxicos (as pernas e os primórdios das asas) são visíveis e afastados do corpo, especialmente quando vistas dorsalmente. Esta fase, apareceu de final de setembro (24) até o início de dezembro (08), com pico em novembro (figura 1E). Sireduzindo assim a longevidade. Razão pela qual a sobrevivência das fêmeas foi de apenas $75 \%$ aos 60 dias. Machos acasalados também têm a longevidade reduzida por perda de energia, tendo vida mais curta, com sobrevivência de apenas $45 \%$ no mesmo período.

Considerando as distribuições estacionais dos estágios de $\boldsymbol{S}$. subsignatus (figuras $1 \mathrm{~A}$ a $1 \mathrm{E}$ ), nota-se que o inseto apresenta uma geração por ano sob condições naturais, no plantio direto, em Cruz Alta (RS). Comportamento e danos de $\boldsymbol{S}$. subsignatus, além de ser um inseto univoltino, são semelhantes ao obtido em Mauá da Serra (PR) por HOFFMANN-CAMPO et al. (1991) e em Passo Fundo (RS) por LORINI et al. (1997). Isso indica que as condições ambientais de diferentes locais não alteram a sua biologia. Esta adaptação é confirmada também pela viabilidade, longevidade e sobrevivência do inseto que foram similares às 
Tabela 1 - Desempenho reprodutivo e longevidade de Sternechus subsignatus em soja, para o ano agrícola 1990/91.

\begin{tabular}{|c|c|c|c|c|}
\hline \multirow{2}{*}{$\begin{array}{c}\text { \% de fêmeas em } \\
\text { Oviposição * }\end{array}$} & \multirow{2}{*}{$\begin{array}{l}\text { Ovos/fêmea * } \\
(\mathrm{X} \pm \mathrm{IC}) * *\end{array}$} & \multirow{2}{*}{$\begin{array}{l}\text { Ovos viáveis/fêmea * } \\
\qquad(\mathrm{X} \pm \mathrm{IC}) \text { ** }\end{array}$} & \multicolumn{2}{|c|}{ Longevidade (dias) $(\mathrm{X} \pm \mathrm{IC})^{1} * *$} \\
\hline & & & Fêmea * & Macho * \\
\hline \multirow[t]{2}{*}{$100 \%$} & $158,40 \pm 61,72$ & $141,85 \pm 51,29$ & $112,53 \pm 46,38 a$ & $62,92 \pm 48,36 b$ \\
\hline & Viabili & dade $=89,9 \%$ & & \\
\hline
\end{tabular}

* Total de 20 indivíduos avaliados

${ }^{1}$ Valores médios, na linha, estatisticamente diferentes pelo teste " $\mathrm{t}$ " de Student $(\mathrm{P}<0,05)$.

** X= Média; $\mathrm{IC}=$ Intervalo de Confiança. adultos com menor massa corporal (tabela 2). Nesta tabela, observa-se que adultos coletados em dezembro de 1991 (originários da população que infestou a área experimental no ano agrícola 1990/91) apresentaram menor ganho de peso, refletido possivelmente por uma menor taxa de assimilação de nutrientes e maior consumo de energia.

Mesmo havendo infestação similar de adultos, ovos e larvas nas plantas em 1989/90 e

obtidas por HOFFMANN-CAMPO et al. (1991), que trabalharam no norte do Paraná. LORINI et al. (1997), no entanto, observaram longevidade de 109 dias para os machos, número médio de 212 ovos por fêmeas e período de incubação de 11 dias, demonstrando haver variações desses aspectos biológicos, que podem ser atribuídas às condições de criação do inseto e influência do número de casais usados.

Também comparado a HOFFMANNCAMPO et al. (1991) e LORINI et al. (1997), há variações com relação ao período de ocorrência dos estágios do inseto, que podem ser atribuídas ao efeito adverso do déficit hídrico, temperatura, alimentação, consumo de energia e época de semeadura da soja. Esses fatores podem ser limitantes, especialmente quando da entrada das larvas no solo e da emergência dos adultos do solo. Notou-se que as larvas encontraram dificuldades para penetrar no solo e cavar a câmara larval subterrânea, pela falta de umidade no solo. Fato possivelmente relacionado com a seca de dezembro de 1990 a março de 1991, com apenas 208mm de chuva, contra os mesmos meses de 1989 e 1990, com 677mm. Nesse período, também as larvas sofreram estresse nutricional, pois encontravam-se em alimentação nas plantas, que, com a seca, retardara o desenvolvimento ocasionando queda na qualidade do alimento para o inseto. Como conseqüência, parte da população não completou a fase larval, não conseguiu abandonar a planta, não penetrou no solo e não construiu a câmara no solo, dando origem a
Tabela 2 - Biometria do estágio adulto de Sternechus subsignatus alimentado com soja, em condições naturais.

$$
\mathrm{X} \pm \mathrm{IC}^{1} *
$$

\begin{tabular}{lccc} 
Mês e ano de coleta & & & \\
\cline { 2 - 4 } & Peso $(\mathrm{mg}) * *$ & Comprimento $(\mathrm{mm}) * *$ & Largura $(\mathrm{mm}) * *$ \\
\hline Dezembro de 1990 & $107,20 \pm 8,11 \mathrm{a}$ & $9,45 \pm 0,25 \mathrm{a}$ & $6,49 \pm 0,25 \mathrm{a}$ \\
Dezembro de 1991 & $37,74 \pm 6,96 \mathrm{~b}$ & $8,66 \pm 0,37 \mathrm{~b}$ & $5,94 \pm 0,32 \mathrm{a}$
\end{tabular}

${ }^{1}$ Valores médios seguidos da mesma letra, na coluna, não diferem significativa-

* $\mathrm{X}=$ Média; $\mathrm{IC}=$ Intervalo de Confiança.

** Total de 100 indivíduos avaliados, em cada mês e ano de coleta. mente pelo teste " $t$ " de Student $(\mathrm{P}<0,05)$. 
sas condições inadequadas para o desenvolvimento do inseto, aspecto este que pode fornecer subsídios ao manejo da espécie, visando à previsão da sua ocorrência.

Outro aspecto revelado neste estudo refere-se ao número de pupas + adultos, em novembro, (figura 1E) ser 2 a 3 vezes inferiror ao de larvas encontrado no solo, entre abril e agosto (figura 1D). Isso é um subsídio importante ao seu manejo, especialmente em áreas que no ano agrícola anterior foram observados ataques severos do inseto. Antes de planejar o cultivo de verão seguinte, o grau de infestação deve ser avaliado, preferencialmente na entressafra, de abril a agosto. SILVA (1998) sugere a retirada de amostras de solo, centradas nas antigas fileiras de soja, de 1,0m de comprimento com largura e profundidade de uma pá de corte. Se forem encontrados de três a seis larvas no solo $/ \mathrm{m}^{2}$, existe a possibilidade de, no mínimo, um ou dois indivíduos atingirem o estádio adulto. Este nível de adultos é crítico (HOFFMANN-CAMPO et al., 1990), pois pode causar redução na produtividade da soja, no ano agrícola seguinte. Nessa área, a soja deve ser substituída por espécies não hospedeiras, na qual o inseto não se alimente e não se desenvolva e, conseqüentemente, interrompa o seu ciclo biológico (LORINI, 1997; SILVA, 1997).

\section{CONCLUSÃO}

O inseto $S$. subsignatus é uma espécie univoltina, apresentando uma única geração por ano, quando aparecem os primerios adultos nas plantas de soja, em plantio direto, com os estágios ocorrendo em épocas bem definidas.

\section{REFERÊNCIAS BIBLIOGRÁFICAS}

BONDAR, G. Insectos daninhos e moléstias dos feijões na Bahia. Boletim do Laboratório de Patologia Vegetal, Salvador, n. 9, p. 34-39, 1930

CORSEUIL E., CRUZ, F.Z. da, MEYER, L.M.C. Insetos nocivos à soja no Rio Grande do Sul. Porto Alegre: UFRGS, $1974,36 \mathrm{p}$.
HOFFMANN-CAMPO, C.B., OLIVEIRA, E.B. de, MAZZARIN, R.M. et al. Níveis de infestação de Sternechus subsignatus Boheman, 1836: influência nos rendimentos e características agronômicas da soja. Pesquisa Agropecuária Brasileira, Brasília, v. 25, n. 2, p. 221-227, 1990.

HOFFMANN-CAMPO, C.B., PARRA, J.R.P., MAZZARIN, R.M. Ciclo biológico, comportamento e distribuição estacional de Sternechus subsignatus Boheman, 1836 (Coleoptera: Curculionidae) em soja, no norte do Paraná. Revista Brasileira de Biologia, Rio de Janeiro, v. 51, n. 3, p. 615-621, 1991.

LORINI, I., SALVADORI, J.R., BONATO, E.R. Bioecologia de Sternechus subsignatus Boheman, 1836 (Coleoptera: Curculionidae), praga da cultura da soja. Passo Fundo: EMBRAPA-CNPT, 1997. 38 p. Documentos, 40.

MENDES, D. Notas sobre os curculionídeos da tribo Sternechini (Col. Curculionidae). Revista Brasileira de Entomologia, São Paulo, v. 7, p. 251-256, 1957.

OLIVEIRA, L.J. GARCIA, A., HOFFMANN-CAMPO, C.B., et al. Coró-da-soja Phyllophaga cuyabana. Londrina: EMBRAPA-CNPSo, 1997. 30 p. Circular Técnica, 20.

PANIZZI, A.R., CORRÊA, B.S., GAZZONI, D.L. et al. Insetos da soja no Brasil. Londrina: EMBRAPA-CNPSo, 1977. 20 p. Boletim Técnico, 1.

ROSADO NETO, G.H. Dimorfismo sexual e distribuição geográfica de Sternechus subsignatus Boheman, 1836 (Coleoptera: Curculionidae) no Brasil. Anais da Sociedade Entomológica do Brasil, Porto Alegre, v. 16, n. 1, p. 199204, 1987.

SILVA, A.G.d'A., GONÇALVES, C.R., GALVÃO, O.M. et al. Quarto catálogo dos insetos que vivem nas plantas cultivadas do Brasil; seus parasitos e predadores. Rio de Janeiro: Ministério da Agricultura, 1968. v. 1, pt. 2, 622 p.

SILVA, M.T.B. da. Aspectos ecológicos de Sternechus subsignatus Boheman (Coleoptera: Curculionidae) em soja no plantio direto. Anais da Sociedade Entomológica do Brasil, Londrina, v. 27, n. 1, p. 47-53, 1998.

SILVA, M.T.B. da, KLEIN, V.A. Efeito de diferentes métodos de preparo do solo na infestação e danos de Sternechus subsignatus (Boheman) em soja. Ciência Rural, Santa Maria, v. 27 , n. 4 , p. $533-536,1997$.

SILVA, M.T.B. da. Comportamento de Sternechus subsignatus (Boheman) em dez espécies vegetais de verão para rotação de culturas ou cultura armadilha no plantio direto. Ciência Rural, Santa Maria, v. 27, n. 4, p. 537-541, 1997.

Ciência Rural, v. 29, n. 2, 1999. 